\title{
Conteúdo de Matemática no Exame de Admissão: memórias de professoras aposentadas
}

\author{
Zélia Maria de Arruda Santiago ${ }^{1}$ \\ Maria de Fátima Caldas de Figueirêdo ${ }^{2}$
}

\section{RESUMO}

Este artigo discute o conteúdo da Matemática em vigor no Exame de Admissão ao Ginásio, adotado no sistema escolar brasileiro nas décadas 40-70 do século XX, tendo-se como referencial de análise narrativas de professoras pedagogas aposentadas e o livro de admissão por elas utilizado. As narrativas revelam experiências da formação continuada condicionada a sua aprovação, nelas, verificando-se conteúdos matemáticos adotados ou não no manual de admissão analisado. Esta discussão funda-se na abordagem qualitativa ao interpretar fontes bibliográficas, documentais e orais. Ao estabelecer uma relação entre as narrativas das professoras e as propostas do conteúdo matemático contidos no manual do Exame de Admissão, constatam-se conteúdos distantes da sua formação escolar e prática docente. Verifica-se que as professoras enfrentaram situações pedagógicas desafiadoras à formação docente, pois deveriam aprender conteúdos não vivenciados na formação escolar e atuação docente.

PALAVRAS-CHAVE: Conteúdo de Matemática. Exame de Admissão. Memórias de professoras.

Admission Exam Math Content: Memories of Retired Teachers

\section{ABSTRACT}

This article discusses the content of Mathematics in force in the

\footnotetext{
${ }^{1}$ Doutora em Educação e professora da Universidade Estadual da Paraíba-UEPB, Campina Grande, Paraíba, Brasil. https://orcid.org/0000-0001-9311-6990.zeliasantiago@yahoo.com.br.

${ }^{2}$ Mestranda em Ensino de Ciências e Educação Matemática pela Universidade Estadual da Paraíba-UEPB, Campina Grande, Paraíba, Brasil. https://orcid.org/0000-0002-6322-754X.fatimaufcg@gmail.com.
} 
Gymnasium Admission Examination, adopted in the Brazilian school system in the 40-70s of the 20th century, having as reference the analysis narratives of retired pedagogical teachers and the admission book used by them. The narratives reveal experiences of continuing education conditioned to their approval, in them, verifying mathematical contents adopted or not in the analyzed admission manual. This discussion is based on the qualitative approach when interpreting bibliographic, documentary and oral sources. By establishing a relationship between the teachers' narratives and the proposals for the mathematical content contained in the Admission Examination manual, contents are found that are distant from their school education and teaching practice. It appears that the teachers faced pedagogical situations that were challenging to teacher education, as they should learn content not experienced in school education and teaching performance.

KEYWORDS: Math Content. Admission Exam. Memories of teachers.

Examen de admisión Contenido matemático: recuerdos de maestros jubilados

\section{RESUMEN}

Este artículo discute el contenido de Matemáticas vigente en el Examen de admisión al gimnasio, adoptado en el sistema escolar brasileño en los años 40-70 del siglo XX, teniendo como referencia las narrativas de análisis de los maestros pedagógicos retirados y el libro de admisión utilizado por ellos. . Las narraciones revelan experiencias de educación continua condicionadas a su aprobación, en ellas, verificando contenidos matemáticos adoptados o no en el manual de admisión analizado. Esta discusión se basa en el enfoque cualitativo al interpretar fuentes bibliográficas, documentales y orales. Al establecer una relación entre las narrativas de los maestros y las propuestas para el contenido matemático contenido en el manual del examen de admisión, se encuentran contenidos que están lejos de su educación escolar y práctica docente. Parece que los docentes se enfrentaron a situaciones pedagógicas que constituían un desafío para la formación docente, ya que debían aprender contenidos que no tenían experiencia en educación escolar y rendimiento docente.

PALABRAS CLAVE: Contenido matemático. Examen de admisión. Recuerdos de profesores. 
Escrever com a contingência da vida é saber transitar no tempo que passa dirigindo-se ao passado, bebendo de suas fontes e enlaçando-o ao presente e ao futuro sempre incerto.

Ângela Mucida

\section{Introdução}

Este trabalho apresenta recortes de uma pesquisa de mestrado ora desenvolvida com professoras aposentadas da zona rural no Município de Barro (CE), focada em narrativas escolares de professoras idosas relacionadas à disciplina de Matemática, como alunas e docentes no curso primário em meados do século XX, décadas 40-70. A memória pode ser compreendida como a capacidade de relembrar vivências que permanecem no sistema cognitivo das pessoas e, ao serem narradas, podem ser ressignificadas ao longo da vida por seus protagonizadores, pois a mesma "constitui-se de traços das experiências vividas, sentidas ou imaginadas" por quem as experienciaram (MUCIDA, 2009, p.15). O protagonista ao narrar não limita-se a informações pertencentes à cronologia temporal, mas, remete-se a uma realidade social, conforme Halbwachs (2003), significando a memória social como uma reconstrução seletiva do passado, este, não pertencente apenas ao indivíduo, mas aos sujeitos envolvidos no contexto social onde se inserem, constituindose uma memória coletiva, a exemplo da memória educacional.

Nesse sentido, a escola como instituição de ensino formal ocupa um lugar de destaque na vida social das pessoas que a ela tiveram acesso, principalmente devido ao papel na memória coletiva de um dado grupo. A escola enquanto um ambiente de muitas representações está repleto de memórias e experiências, geradoras de histórias compostas por várias personagens que, mesmo em épocas e locais semelhantes, experienciaram diferentes narrativas de vida. De forma mais específica, por meio de narrativas é possível identificar dificuldades em relação à aprendizagem da Matemática, pois estas não são remetentes apenas a tempos passados, mas a uma realidade vivenciada por muitos alunos, ainda que refletidas em 
diferentes épocas com outros cenários e protagonistas.

O currículo da Matemática escolar vigente na atual Educação Básica, é resultado de constantes mudanças, tanto em relação às propostas do conteúdo a ensinar, quanto à metodologia e à prática doecente. Interessa discutir os conteúdos matemáticos trabalhados no recorte temporal das décadas 40-70 do século XX, equivalente ao ensino primário, verificando sua proposta de preparação para o Exame de Admissão. Este exame seletivo para o ingresso no curso ginasial foi um mecanismo de avaliação institucional obrigatório, uma proposta curricular oficial existente até o ano de 1971, o qual faz parte da memória educacional não apenas de professoras cearenses, mas de outras nos demais Estados da federação, haja vista a atuação feminina no magistério primário (SAVIANI, 2004). Temido por muitos, ao considerá-lo desafiante, devido a presença dos conteúdos da Matemática, realidade evidenciada nas narrativas das professoras aposentadas.

Elas descrevem não apenas desafios quanto a preparação psicológica, mas, acerca da aprendizagem do contéudo ao vivenciarem experiências de êxito ou não, pelo fato de serem, ao mesmo tempo, alunas e docentes inseridas neste cenário de formação continuada. Nos relatos de memórias, das professoras aposentadas docentes do curso primário, têm-se recortes de experiências diferenciadas, mas considerados importantes ao legado da história educacional brasileira, pois foram narrados por mulheres idosas, capazes de registrar experiências didático-pedagógicas referentes às práticas docentes no contexto educacional do Ceará. Neste sentido, entende-se o pretérito se refazendo no presente, ainda que muitos não percebam que a "incompreensão do presente nasce fatalmente da ignorância do passado" (BLOCH, 2001, p. 65), isto sendo o passado determinando o presente, tendose um processo interdependente entre passado-presente, ambos se refazendo um no outro. Por isso, consideramos relevantes as narrativas das memórias escolares das professoras idosas num contínuo processo histórico se recompondo no tempo presente.

As narrativas de vivências e experiências das professoras pedagogas 
que não tem Licenciatura em Pedagogia, mas são assim denominadas pelo fato de ministrarem aulas para crianças, transmitem informações importantes à construção da realidade educacional brasileira, consideradas fontes que informam sobre a instituição escolar, metodologia, perfil socioeducacional dos professores, conteúdo das disciplinas, a exemplo da Matemática, acesso e permanência dos alunos na escola, formação docente para o ensino primário, avaliação, aprendizagem, etc., por elas vivenciadas em épocas passadas, mas presentes nos seus depoimentos atuais. Em suas narrativas há marcas de superação quanto a formação educacional neste nível de atuação primária, muitas vezes, por enfrentarem a desvalorização social desta profissão, pois não tinham condições de trabalho apropriada, salário baixo e não contavam com acompanhamento pedagógico. Essas narrativas de experiências são valorizadas por enfrentarem, no presente, a imagem da velhice, muitas vezes, percebida na sociedade como de pessoas silenciadas, improdutivas, distantes da produção dos saberes matemáticos.

Neste trabalho considera-se que as professoras idosas aposentadas ao narrarem experiências docentes continuam produzindo saberes-fazeres da Matemática, pois suas experiências pedagógicas geram práticas mais elaboradas não, facilmente, descartadas por originarem-se de vivências individual e coletiva que não se apagam (MUCIDA, 2009). Através de seus relatos de memórias sabe-se de suas dificuldades para aprenderem e ensinarem o conteúdo da Matemática, ao vivenciarem um processo seletivo, obrigatório e decisivo na continuação da formação escolar e acadêmica, muitas vezes, não acessada por muitos na sua época, o Exame de Admissão que consistia em um processo seletivo obrigatório para o aluno cursar o Ginásio. Com este foco temático consideram-se as discussões teóricas da Matemática escolar referente ao recorte estudado, décadas 40-70 do século XX (AKSENEN, 2013), os conteúdos prescritos no livro preparatório para o Exame de Admissão (SILVA, 2018), bem como as contribuições de autores que discutem memórias escolares em narrativas de professoras pedagogas do campo, as docentes que ministraram aulas na zona rural (SANTIAGO e 
GUIMARÃES, 2017), ao apresentarem experiências de professoras primárias submetidas ao Exame de Admissão para obterem a formação continuada e permanecerem no exercício do magistério, e, ainda, enfrentando dificuldades na formação da Matemática.

\section{Metodologia: Percurso da pesquisa}

Os resultados apresentados são recortes de uma pesquisa de mestrado direcionada à memória escolar de professoras pedagogas aposentadas, mas neste artigo direciona-se sua análise ao currículo da Matemática. Abordamse seus conteúdos trabalhados na preparação para o Exame de Admissão ao Ginásio nas décadas 40-70, século XX, período em que foram submetidas a este exame ao iniciar os primeiros enfrentamentos com os conteúdos da Matemática como alunas-professoras em formação continuada. Esta reflexão aconteceu baseada em narrativas de quatro professoras, pois a seleção do corpus da pesquisa encontra-se em fase embrionária, optando-se pela identificação das participantes, mas representadas com nomes de plantas nativas da região do Cariri cearense, as quais por elas mencionadas ao longo das entrevistas: Aroeira, Jurema, Mofumbo e Imburana.

A pesquisa funda-se em uma abordagem qualitativa com análise interpretativa das informações coletadas em visitação às suas residências, tendo-se como material de discussão as histórias de vida dessas professoras e consulta documental, a exemplo do manual do livro admissão (COSTA, et al 1949), referentes ao conteúdo da Matemática a ele destinado, além de consultas bibliográficas. Procedimentalmente, a pesquisa realizou-se no Município de Barro situado no Cariri cearense com quatro professoras pedagogas, idosas e aposentadas que atuaram na educação campesina nas séries do antigo primário, atualmente, às séries dos anos iniciais do Ensino Fundamental da Educação Básica.

Para a realização de coleta das informações utilizou-se como instrumento um roteiro de entrevista. Após sua realização as narrativas dela 
decorrentes, foram enriquecidas com depoimentos anotados em caderneta de campo, seguindo suas transcrições, além de fotos e documentos, tendo-se a análise apenas trechos narratórios relacionados ao conteúdo de Matemática ligado as dificuldades de aprendizagem e ensino enfrentadadas pelas professoras das séries primárias. Nessa época, referente aos anos 1940-70, muitas dessas professoras ensinavam sem concluir sequer o curso primário, mas para continuarem estudando enfrentavam o Exame de Admissão, neste caso, estudavam todos os conteúdos das séries primárias, pois do contrário teriam dificuldades no seu ensino quando da atuação docente.

\section{Currículo da Matemática: Exame de Admissão ao Ginásio}

É impossível refletir sobre o currículo da Matemática validado em meados do século XX, sem abordar o Exame de Admissão ao Ginásio, pois este marcou a trajetória escolar da formação e atuação das professoras aposentadas que fizeram parte da pesquisa, além de tantos estudantes que desejavam a continuidade da formação educacional. O objetivo do Exame Admissão era preparar alunos para o ingresso no curso ginasial (séries escolares correspondentes ao Ensino Fundamental II), um processo seletivo institucional existente na época, temido por quem o enfrentava. $\mathrm{O}$ desenvolvimento urbano influenciado pelo processo de industrialização exigia mudanças curriculares no sistema educacional, a fim de preparar sujeitos capazes de responderem as demandas de atuação profissional e participação na sociedade.

Neste sentido, a escola se afirma como agência institucionalizada para oferecer à população oportunidades educativas, desta forma, contribuindo para o desenvolvimento científico e profissional dos cidadãos. Historicamente a escola se ajusta as imposições das políticas educacionais adotadas em diferentes períodos históricos, as quais se institucionalizam no contexto educacional nacional, sobretudo em épocas referentes a formação educacional e atuação profissional das professoras no Magistério (décadas 40-70, século 
$\mathrm{XX})$, pois o

[...] exame de Admissão constituiu por décadas a linha divisória entre o ensino primário e a escola secundária; funcionou como um verdadeiro rito de passagem no processo de seleção à continuidade dos estudos, representada pelo ingresso no ginásio acadêmico, que teve procura intensificada a partir dos anos 1930 (VALENTE, 2001 apud AKSENEN, 2013, p.2).

Por meio dessa seleção institucional as professoras dariam continuidade aos estudos da formação escolar no curso ginasial e, após a sua conclusão, continuariam os estudos em nível secundário nos cursos clássicos, profissionalizantes ou no curso normal destinado ao Magistério, o qual trabalharia as didáticas direcionadas às disciplinas do antigo primário, inclusive a Matemática (SAVIANI, 2004). Os conteúdos validados no currículo escolar, exigidos na transição do curso primário ao ginasial, estavam disponibilizados em um único volume preparatório denominado de o "Livro de Admissão ao Ginásio”, o mesmo destinado a todos os estudantes. Este manual, a partir de 1930 ganha destaque editorial em âmbito nacional com ampliação editorial e vendas consecutivas destinadas a professores e alunos que nele, respectivamente, ensinavam e aprendiam, mas extinto mediante configuração organizacional do ensino de $1^{\circ}$ e $2^{\circ}$ graus fixado na Rede Pública Estadual e Municipal conforme a Lei de Diretrizes e Bases da Educação Nacional n 5.692/1971 (SAVIANI, 2004; SILVA, 2018).

Em pesquisas acerca da publicação deste manual contabilizaram tiragens de 559 edições, durante, aproximadamente, 27 anos de sua permanência no mercado editorial da educação (SILVA, 2018). O referido exame exigia de professores ensinantes e, alunos aprendentes, uma etapa de ensino-aprendizagem direcionada a sua realização por meio de prova escrita, nela contendo todos os conteúdos da grade curricular das séries primárias, neste aspecto, muitos professores, sobretudo, alunos a ele se submetiam, a fim de continuarem a formação educacional. 
No cenário educacional este manual deveria ser seguido ao 'pé da letra' prevalecendo o método da memorização dos conteúdos para a efetiva aprovação. O livro analisado foi um exemplar da Coleção Didática do Brasil da série ginasial, referente a $19^{\mathrm{a}}$ Edição, contendo 285 páginas da Editora do Brasil localizada em São Paulo (COSTA, et al 1949), composto pelas matérias exigidas no referido exame: Português, autora Aída Costa, Matemática, autor Renato Pasquale, Geografia, Renato Stempniewski e, História do Brasil, Aurélia Marino, respectivamente. Os conteúdos de cada programa eram escritos e organizados por pessoas das áreas de ensino, quer dizer, pelos professores responsáveis por cada matéria, tendo-se a ilustração da capa externa e folha de rosto com identificação dos elementos pré-textuais do livro “Admissão ao Ginásio" (Figura 1).

Figura 1: Capa e folha de rosto livro "Admissão ao Ginásio" (1949)

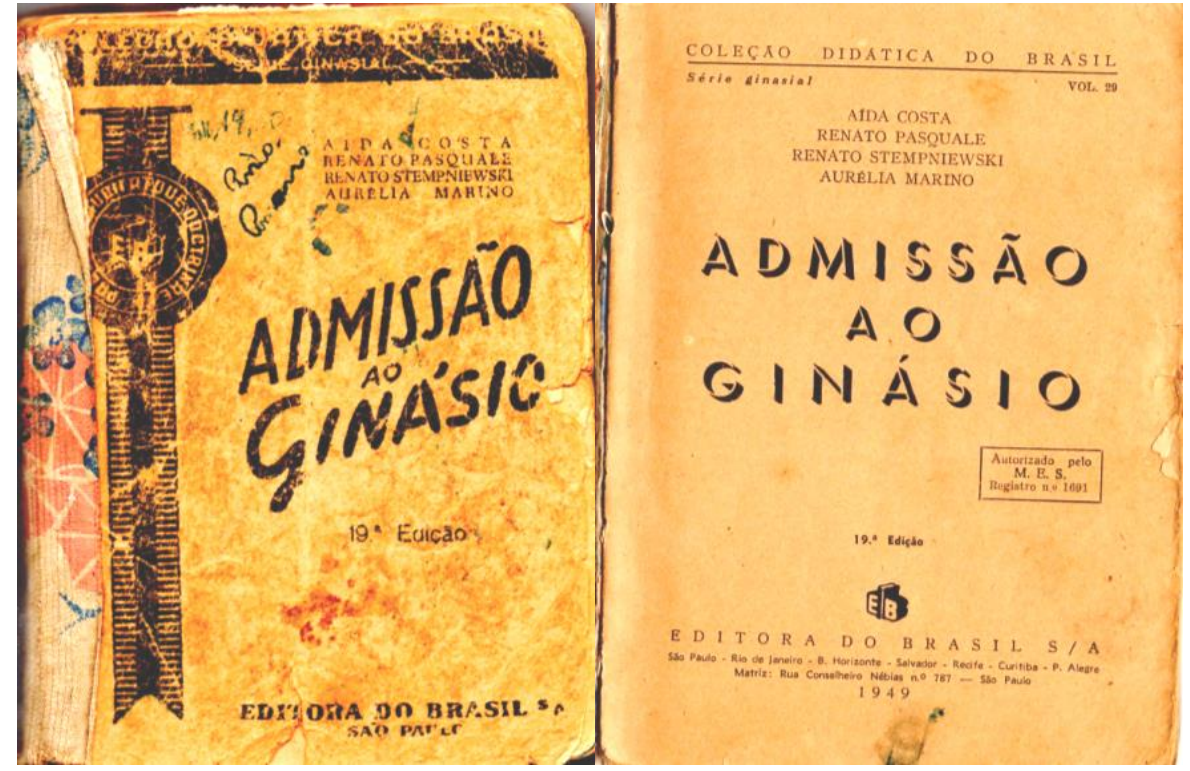

Fonte: Arquivo pessoal da professora aposentada Aroeira(Pesquisa realizada pelos autores,2019)

Nesta capa verifica-se reparos improvisados, talvez com uso de tecido caseiro para sustentar sua antiga encadernação, revelando cuidados da parte da professora por este documento educacional, caracterizado em sua temporalidade (1949) nas folhas amareladas. Na capa e folha de rosto verificam-se o selo editorial e logomarca da editora, rabiscos cor de azul, 
talvez registrados com caneta-tinteiro, significando marcas do tempo impregnadas neste documento repleto de lembranças educacionais. Os reparos não significam apenas vestígios de restauração documental, mas a vontade cuidadosa de continuar a aprender frente à necessidade da preparação para atuar no magistério, conforme lembranças narradas pela professora "Aroeira", ao mencionar que "esse foi o livro que me preparei pra fazer o Exame de Admissão, e depois continuei usando ele pra preparar os meus aluno (sic)". Por meio da aprovação no Exame de Admissão esta professora, assim como outras, não apenas superavam obstáculos no aprendizado e ensino da Matemática, mas alcançavam conquistas educacionais e profissionais mediante "a aprovação no Exame de Admissão ao Ginásio era sinal que a pessoa iria avante", conforme destaca a professora mencionada.

Neste sentido, trabalhos de pesquisas com narrativas de professoras campesinas acerca da fase preparatória de ingresso no ginásio, geralmente oferecido em escolas urbanas, evidenciam tamanha ansiedade que muitas enfrentavam, por isso, algumas logo se interessavam pela aquisição do livro admissão. Neste sentido, Santiago e Guimarães (2017, p. 98-99) revelam quão grande era esse sentimento vivenciado por uma das professoras em relação à fase preparatória ao exame admissão, ao relembrar da "vontade tão grande que eu tinha de entender, me peguei com o livro de admissão, decorei o livro quando tava se preparando para o admissão só era todo no livro, eu nunca li outro livro para o admissão". Esta professora, inserida noutro contexto social e realidade educacional do Estado da Paraíba, enfrentava as exigências das mudanças no ensino e na formação docente, constatando-se suas dificuldades, mas, identificando-se suas estratégias de aprendizagem em torno da aprovação do exame por meio da memorização.

O programa da Matemática era organizado conforme alterações normativas de cada secretaria educacional do Estado, mas, seguindo a dinâmica das transformações sociais implantadas por meio de portarias, circulares, decretos e ofícios institucioais, dentre outros documentos validados 
neste contexto e época. Estes mecanismos regularizavam normas da realização do exame admissão e validade dos conteúdos, sendo possível verificá-los estes conteúdos, retirados do manual analisado, apresentados no Quadro 1.

Quadro 1: Contéudo da Matemática vigente no Curso de Admissão ao Ginásio

\begin{tabular}{|l|l|}
\hline Comparação de frações. & Número. Algarismos arábicos e romanos. \\
Números decimais. & Numeração decimal: unidade das diversas \\
Operações sobre números decimais. & ordens, leitura e escrita dos números \\
Conversão das frações ordinárias em & inteiros. \\
decimais e vice-versa. & Operações fundamentais sobre os \\
Exercícios fáceis sobre expressões em que & números inteiros. \\
entrem frações ordinárias e decimais, para a & Prova real e dos nove. \\
aplicação das regras de conversão e das & Divisibilidade por 10, 5, 2, 9, 3e 11. \\
operações. & Número primo. \\
Noções do sistema métrico decimal. & Decomposição de um número em fatores \\
Metro; sua definição; metro quadrado e & primos. \\
metro cúbico; múltiplos e submúltiplos. & Máximo divisor comum. \\
Litro; seus múltiplos e submúltiplos. & Mínimo múltiplo comum. \\
Grama; sua definição e seus múltiplos e & Fração ordinária. \\
submúltiplos. & Fração própria, imprópria, número misto. \\
Sistema monetário brasileiro. & Extração de inteiros. \\
Resolução de problemas fáceis, inclusive & Simplificação de frações e redução ao \\
sobre as medidas do sistema métrico & mesmo denominador. \\
decimal. & \\
\hline
\end{tabular}

Fonte: COSTA, A, et al (1949)

Ao analisar este manual percebe-se que o programa dos conteúdos de Matemática, nem sempre contendo conteúdos referentes às séries do curso primário, era extenso, apresentando-se maior que os conteúdos de História do Brasil e Geografia. Muitos dos conteúdos de Matemática aparecem nas narrativas das professoras, conforme a professora "Aroeira" menciona que, "naquele tempo em Matemática era fração ordinária, decimal, sistema métrico, operações, só essas coisas assim, álgebra não tinha não”. Esta professora revela diferenças entre o conteúdo programático do curso primário e o programa no livro de admissão, ao referir-se que a "álgebra" estaria na programação do exame. Neste caso, as professoras sentiam dificuldades por não dominarem este conteúdo unificado de abrangência nacional, conforme o decreto $\mathrm{N}^{\circ} 19.890$ de 18 de abril de 1931, atentando para a abordagem 
pedagógica subjacente às questões da Matemática relacionada ao referido conteúdo, certamente distante dos seus domínios de aprendizagem e experiências docentes.

A necessidade de aprender estes contéudos programáticos e, até, decorá-los identifica que as professoras passaram pela experiência da preparação e seleção do Exame de Admissão, cuja realidade reflete o cumprimento dos pré-requisitos educacionais estabelecidos nesse recorte histórico. A professora protagoniza uma motivação de obrigatoriedade ao compreender as relações existentes entre diferentes conteúdos matemáticos, embora sua aprovação demonstrasse a capacidade dos alunos acompanharem o conteúdo a ser tratado no curso ginasial (AKSENEN, 2013). Assim, os conteúdos de Matemática eram abordados no livro de admissão em conformidade com o programa seletivo, sugerindo métodos de aprendizagem de memorização de conceitos, operações e regras.

A exposição dos conteúdos aparecem em forma de esquemas e tabelas que trabalham exemplos e orientam os alunos a montarem os cálculos, tirarem provas e realizarem as operações. Esta metodologia simplificada ao expor conteúdos mais complexos da Matemática interferia na compreensão das professoras, conforme relata a professora "Mofumbo" ao mencionar que "na Matemática eu só era boa nas contas, às quatro operações eu era boa, aprendi, agora as frações, expressões aritméticas, aquele negócio de abre parênteses e fecha parênteses, atrapalhava mais a minha mente", verificandose domínios de aprendizagem diferenciados da parte da professora. Percebese que o conteúdo das operações básicas predominava nas práticas do ensino primário e de aprendizagem das professoras, assim, eram desafiadas a aprender novos contéudos com outras técnicas de aprendizagem, como a memorização das propriedades e regras matemáticas a serem compreendidas e aplicadas.

Esta ausência de aprendizagem ampliava a incompreensão do contéudo matemático, pois a professora "Imburana" afirmou que na época do Exame de Admissão "eu vi uma Matemática tão difícil, complicada, eu nunca tinha visto 
tão difícil daquele jeito”, verificando-se situações desafiadoras vivenciadas por elas frente às exigências da formação continuada. Da mesma forma que os conteúdos sustentavam-se em uma abordagem simplista, igualmente, as atividades de avaliação se estruturavam de forma mais resumida, geralmente em forma de "exercícios", constituídos de questões simples de calcular, efetuar contas e tirar provas, decompor números, etc. No manual verifica-se a parte dedicada aos "questionários" que trabalhavam conceitos e definições dos conteúdos de forma específica e direta. A seção dos "problemas" contempla questões mais contextualizadas em termos da realidade de atuação e aprendizagem das professoras, mas, sempre utilizando uma linguagem centrada no conteúdo temático. A maneira como as questões eram aboradadas no livro de preparação para o Exame de Admissão ao Ginásio, refletia o saber padronizado no processo seletivo.

Esta padronização representava instruções nacionais deliberadas por instituições educacionais responsáveis pela realização do exame escrito de admissão. Neste sentido, prevalecia a avaliação escrita no sistema educacional brasileiro, pois "a prova escrita de Matemática visa de modo especial, apurar o domínio das operações fundamentais e o desembaraço no cálculo" por meio da escrita (BRASIL, 1940, apud AKSENEN, 2013, p.88). Na época de atuação e formação continuada das professoras o Exame de Admissão prevalecia como único meio de entrada no curso ginasial, para tanto, os estudantes deveriam dominar bem a Matemática, especialmente os conteúdos referenciados na grade curricular da época.

\section{Exame de Admissão ao Ginásio: Memórias de professoras}

Conforme as narrativas das professoras verifica-se que Exame de Admissão era um processo seletivo na transição do curso primário ao ginasial, adotado por muitos anos no sistema educacional brasileiro, fazendo parte da história não só de professores cearenses, mas de outros professores em diferentes contextos nacionais, a exemplo da Paraíba. Esse exame era uma 
prova obrigatória institucionalizada nas políticas públicas da educação brasileira disseminada, sobretudo, na escola pública. No período de preparação dos estudantes o manual vigente era muito requisitado por seus pais, também, preservado como relíquia e lembrança de um período difícil de aprendizagem e continuidade da formação escolar.

A memória das professoras revelam a valorização social do Exame de Admissão para as famílias, os alunos e o contexto histórico, sua importância para os que buscavam a continuidade da formação escolar. Neste sentido, a professora "Aroeira" lembra que "estudei em Juazeiro do Norte-CE no Ginásio de Santa Terezinha, adquiri muitos conhecimentos lá. Quando terminei vim pra cá, naquele tempo era difícil professora, pra essas cidades pequenas". Neste contexto e época a referida professora teve condições de sair do sítio para estudar em uma cidade mais desenvolvida, consequentemente, obtendo sucesso na continuidade dos estudos, como a formação para o magistério.

Todavia, para esse exame seletivo obrigatório, por ser o único meio de ascensão escolar, nem todos tinham condições de se preparar na maioria das vezes, não podiam comprar o livro básico ou sequer tinham condições para realizar o curso ginasial noutro lugar. Nesta época a escola pública não havia sido disseminada no contexto do Brasil, portanto, escassa em muitas cidades, uma instituição inexistente na zona rural (SAVIANI, 2004).

Outro caso refere-se à professora "Jurema" que não teve a mesma narrativa de vida lembrada ao afirmar que "eu fiz a $4^{a}$ série umas quatro vezes, só repetindo, porque não tinha a continuação dos estudos por aqui, só era possivel pra mim em Fortaleza, porque a gente tinha parente lá pra eu ficar, mas é muito longe" e, ao concluir este trecho narratório, afirma que era "doida pra estudar, mas como? Meus pais pobres, não tinha (sic) como pagar. Depois apareceu o Admissão por aqui e eu fiz... precisava aumentar o meu saber". Entre as professoras percebe-se vivências de formação continuada diferenciadas devido às dificuldades de acesso e permanência escolar, bem como de atuação pedagógica e formação continuada.

A professora aposentada "Mofumbo" narrou sua realidade enquanto 
aluna ao evidenciar que o ensino "era tudo particular, tudo os pais quem pagavam... era difícil estudar naquela época, porque os pais que tinha (sic) um monte de filho não podia (sic) pagar estudo só com o dinheiro que conseguia (sic) na agricultura”. Destaca a realidade desse período em relação ao ensino gratuito não, totalmente, disseminado na federação, cuja realidade vivida nas comunidades rurais tornava-se mais desafiadora por conta da mobilização, condições financeiras e inexistência de escolas na zona rural ou cidades próximas. Esta professora continua sua narrativa ao afirmar que, "além das dificuldades que a gente passava, ainda tinha a Matemática, conteúdo difícil, pior de todas ... foi o primeiro desafio no Exame de Admissão ao Ginásio”. As professoras evidenciam uma escrita histórica inscrita nos registros da memória educacional individual, social e coletiva, por meio das quais as narrativas educacionais circulantes no presente são refletidas a partir daquelas.

\section{Conclusão}

A partir das discussões em torno dos conteúdos trabalhados no Exame de Admissão ao Ginásio, registra-se que para o aluno ser aprovado neste exame teria que dominar bem os conteúdos da Matemática, situação não diferenciada dos exames de avaliação nacional atuais. Mas, para muitas esta habilidade com os conteúdos da Matemática exigidos no Exame de Admissão não fazia parte da realidade das professoras participantes da pesquisa, outras, não encararam esta disciplina como obstáculo de aprovação.

Frente a novos conteúdos para aprender e diante da ansiedade por enfrentar um exame, por elas classificado como rigoroso, em termos da quantidade de conteúdos, a metodologia da memorização, as dificuldades de acessar o manual, as professoras enfrentaram dificuldades e narraram suas experiências de formação e atuação docente. As professoras enfrentavam dificuldades de entender a organização dos conteúdos no livro de admissão, pois nele se concentrava todos os conteúdos, muitos deles jamais estudados 
por elas, portanto, um exemplar específico que não fazia parte do seu cotidiano escolar de ensino, aprendizagem e formação docente. As atividades e os conteúdos, nele apresentados, diferenciavam-se das questões trabalhadas e estudadas em sala de aula, por isso, elas enfatizam que estudavam bastante para enfrentar esta seleção.

No exemplar analisado verificou-se tipos de atividades que, adotadas, atualmente, em livros didáticos de Matemática muito próximas da estrutura apresentada no livro de admissão, a exemplo das questões simplificadas, descontextualizadas da prática, muitas vezes, priorizando operações para efetuar, calcular ou definir centradas no conteúdo. Por meio desta pesquisa as professoras tiveram a oportunidade de narrar um pouco das experiências enquanto alunas-professoras, em meados do século XX, décadas 40-70. Ao mesmo tempo permitiu a outras pessoas conhecerem a realidade educacional desse contexto histórico no Estado do Ceará, cujas experiências apresentadas são próximas da realidade educacional vivenciada em outros Estados da federação, a exemplo da Paraíba, conforme os resultados da pesquisa realizada por Santiago e Guimarães (2017) no referido estado. Estas memórias informam sobre a escola, a metodologia, o conteúdo da Matemática, o acesso e a permanência na rede escolar, a continuidade da formação educacional, memórias remetentes a épocas passadas, mas evidentes em situações do ensino da Matemática atual.

Mas ao confrontar situações atuais da formação e prática docente como professora dessa disciplina, percebe-se que houve crescentes mudanças no seu ensino, igualmente, no currículo, nos documentos oficiais, a exemplo da Base Nacional Comum Curricular (BNCC), nas diretrizes curriculares, como os Parâmetros Curriculares Nacionais (PCN) e nas leis educacionais, a Lei de Diretrizes e Bases da Educação Nacional (LDB) que contribuem para tornar o ensino da Matemática mais acessível frente às transformações sociais. Por meio dos autores que dialogam com esta temática entende-se que o Exame de Admissão proporcionou crescimento, quanto ao conhecimento matemático, uma vez que as professoras precisaram estudar a disciplina para serem 
aprovadas, contribuindo desse modo com a formação e atuação docente, sobretudo a superação no conteúdo da Matemática, ao qual elas se dedicaram para aprender. Não foi apenas uma prova obrigatória existente oficialmente até 1971, mas um processo de crescimento pessoal e pedagógico na formação continuada conforme demandas da época. Com suas narrativas observa-se a necessidade de outros trabalhos envolvendo narrativas de pessoas idosas como fonte de pesquisa e acervo sociocultural, consideradas fontes de memórias, vivências, experiências e informações pelas quais o presente compreende o passado, para melhor refleti-lo e planejar ações educacionais continuadas e partilhadas entre as gerações.

\section{Referências}

AKSENEN, E. Z. Os exames de admissão ao Ginásio, seu significado e função na educação paranaense: análise dos conteúdos matemáticos (1930 a 1971). 2013. 145p. Dissertação (Mestrado em Educação) - Pontifícia Universidade Católica do Paraná, Escola de Humanidades, Curitiba, 2013.

BLOCH, M. Apologia da História ou o Ofício de Historiador. RJ: Jorge Zahar, 2001. BORTONI-RICARDO, S. M. O professor pesquisador. São Paulo, Parábola, 2008.

COSTA, A; PASQUALE, R; STEMPNIEWSKI, R; MARINO, A. Admissão ao Ginásio. Coleção Didática do Brasil, Série ginasial. São Paulo: Editora do Brasil, 1949.

HALBWACHS, M. A Memória Coletiva. Beatriz Sidou (trad.) SP: Centauro, 2003.

MUCIDA, Â. Escrita de uma memória que não se apaga-Envelhecimento e velhice. Belo Horizonte: Autêntica, 2009.

SANTIAGO, Z.M.A., GUIMARÃES, Z.M.A.S. Narrativas de Professora do campo: Saberes ditos, experiências lidas e cunhadas em letras. Vol. I, Curitiba: CRV, 2017.

SAVIANI, D. et al. O legado educacional do século XX no Brasil. Campinas, SP: Autores Associados, 2004.

SILVA, C. B. Era uma uma vez... uma editora, um livro: Admissão ao ginásio, Editora do Brasil (Décadas 1940-1960). In: Revista Brasileira de História da Educação (v. 18, 2018). ISSN: 2238-0094, 2018.

Recebido em dezembro de 2019.

Aprovado em março de 2020. 